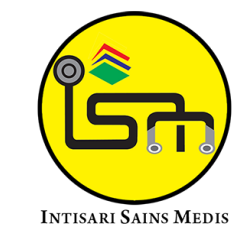

Published by Intisari Sains Medis

\section{Tuberculosis cases comparison in developed country (Australia) and developing country (Indonesia): a comprehensive review from clinical, epidemiological, and microbiological aspects}

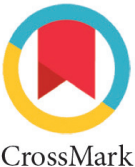

CrossMark

\author{
Ni Luh Putu Harta Wedari ${ }^{1 *}$, I Wayan Adi Pranata², \\ Ni Nyoman Sri Budayanti ${ }^{3}$, I Dewa Made Sukrama ${ }^{3}$
}

${ }^{1}$ Clinical Microbiology Residency Program, Faculty of Medicine, Universitas Udayana, Sanglah General Hospital, Bali, Indonesia;

${ }^{2}$ Indonesia Research Partnership on Infectious Diseases (INA-RESPOND), Jakarta, Indonesia; ${ }^{3}$ Clinical Microbiology Department, Faculty of Medicine, Universitas Udayana, Sanglah General Hospital, Bali, Indonesia.

*Corresponding author:

Ni Luh Putu Harta Wedari;

Clinical Microbiology Residency Program, Faculty of Medicine, Universitas Udayana, Sanglah General Hospital, Bali, Indonesia;

hartawedari@gmail.com

Received: 2021-05-04

Accepted: 2021-06-19

Published: 2021-06-22

\section{ABSTRACT}

Background: Tuberculosis (TB) is one of most crucial public health issues around the world. TB is an entity of a complex disease with the socio-economic aspect that has very strong correlation in regard to combat this disease. Migration from developing country to developed country inevitably possesses big influence on global epidemiologic of TB. In Australia, TB still becomes the main threat not only in native population but also regarding the migrant movement into Australia. Indonesia is one of among the TB endemic countries with high TB cases, in which not merely due to its high TB prevalence and incidence but also influenced by very high and dense population.

Aim: This literature aims to review the clinical, epidemiological, and microbiological aspects of tuberculosis as a comparison between developed country (Australia) and developing country (Indonesia). Conclusion: Tuberculosis cases in Australia remains low compared to Indonesia, however, the close proximity to adjacent developing countries with high endemic of TB contributes significantly to increase number of TB in Australia. Tuberculosis can be cured by following the treatment guidelines with proper monitoring. Moreover, the collaboration between public and private sector along with active collaboration from the family or people surrounding the patients is required to eliminate TB disease.
Keywords: tuberculosis, clinical, epidemiological, microbiological, migration, public health.

Cite This Article: Wedari, N.L.P.H., Pranata, I.W.A., Budayanti, N.N.S., Sukrama, I.D.M. 2021. Tuberculosis cases comparison in developed country (Australia) and developing country (Indonesia): a comprehensive review from clinical, epidemiological, and microbiological aspects. Intisari Sains Medis 12(2): 421-426. D0I: 10.15562/ism. v12i2.1034

\section{INTRODUCTION}

Tuberculosis is one of most crucial public health issues around the world, especially in the developing country. Despite the significant drop of TB incidence in last few decades, there are around 10 million new people suffering from $\mathrm{TB}$ and death was noted to be around 1.5 million cases happened in 2019. ${ }^{1}$ TB is such a complex issue as it is not merely concern about the disease itself but also socio-economic aspect that has very strong correlation in regard to combat this disease. Throughout the years, TB is pretty much poverty-related condition whereas TB mostly infects the community in developing country or poor nations where the sanitation has very low quality. Moreover, such circumstances become more complicated when it comes to multi drugs resistant of Mycobacterium tuberculosis in many countries make it even challenging to conduct the successful control goal. Effort of early detection of TB notification cases remains a big challenge especially in the country where the health resources are limited and TB cases in HIV patients where the HIV marked as negative stigma in the community, subsequently TB cases become such an iceberg phenomenon where the number does not show the real cases undiagnosed or unnoticeable. World Health Organization (WHO) has established the latest global
TB approach to achieve the elimination of TB worldwide in 2035. That master plan consists of patient center TB management, policy and supportive means, and intense research and innovative solution. ${ }^{1,2}$

Migration inevitably possesses big influence on global epidemiology of TB. It is estimated around 230 million international individual migrates crossing the borders in between many different countries annually, from developing country where TB concentrates and has large proportion, to developed country, vice versa. TB is easily expanded from one area to other area in regard to the people movement. Inevitably, those migrants mean the major $\mathrm{TB}$ infection reservoir in 
various low endemic areas. Even though those individuals were healthy on the arrival at destination country, they were on latent infection of Mycobacterium tuberculosis. Favorably, such lifestyle changes could contribute to weak immune system, leading the TB becomes active disease. Ineluctably, worse conditions such as poverty, over dense population, low sanitation are significant contributors for the spreading of $\mathrm{TB} ., 3,3,4,5$

In Australia, TB still becomes the main threat not only in native population but also regarding the migrant movement into Australia. According to Northern Territory Centre for Diseases Control more than 9 million TB new cases in the world, of which 13,000 were the ones in Australia. Among those new cases, most of them originally come from high endemic countries where the TB became major prevalence in advance. However, little spread occurred in some of Northern Territory in 2016. Having said that, TB rates on indigenous population have significantly dropped around $65 \%$ in last decade due to effective prevention and control according to CDC. Management of TB is multi aspects management, start from early detection, prompt treatment and control the patient management due to its long duration. Moreover, TB management is struggling with the stigma whereas it is mostly founded in people with immunocompromised or immunodeficiency such as HIV should be concerned. ${ }^{3,4,5}$

In neighboring country, Indonesia is one of among the TB endemic countries with high TB cases, in which not merely due to its high $\mathrm{TB}$ prevalence and incidence but also influenced by very high and dense population residing in Indonesia. Throughout decades, incidence rate has been dropped significantly, but counteract with population rise. However, the detection of case became even greater in which 56 per cent in 2010 became 70 per cent in 2011. Nevertheless, there are still many undetectable $\mathrm{TB}$ cases especially in remote area to be a crucial challenge of the case findings. Moreover, beside the poverty, the great challenges are diagnostic and health care access for suspicious people in out-of-reach regions. Being said that, among 482 regions, 138 of those have been already well known by government, but the rest of them are still far away of community health service center. ${ }^{1,6}$

\section{Mycobacterium tuberculosis ORGANISM}

Mycobacterium tuberculosis is a kind of pathogenic bacteria of Mycobacteriaceae. It is a definitive cause of tuberculosis. Mycobacterium tuberculosis was first invented by Robert Koch in 1882 . Mycobacterium tuberculosis was known as the causative agent of White Plague in $17^{\text {th }}$ and $18^{\text {th }}$ centuries throughout the European countries (Figure 1). During that time, almost 100 per cent of human infected with Mycobacterium tuberculosis in which 25 per cent of those were dead. ${ }^{7,8}$

Microscopically, Mycobacterium tuberculosis is seen to be non-motile with rod-shape (Figure 2). ${ }^{9}$ Looking at its morphology, it is 2-4 ìm length, 0.2-0.7 ìm width. It is known as obligate aerobe meaning it needs sufficient amount of oxygen to continue to live hence the bacteria packed always resides in upper lobes of pulmonary lobes, because the aeration ventilation is well enough. Besides, the characteristic of bacteria makes it as facultative intracellular parasite in macrophage, it also has very slow degeneration interval time which is 15 until 20 hours. Mycobacterium tuberculosis can be died if they are directly being exposed with UV light. Conversely, the bacteria can persist in very low temperature around $4^{\circ} \mathrm{C}$ until $-70^{\circ} \mathrm{C}^{7,8}$

The most significant attribute of its virulence is the cell wall consisting of

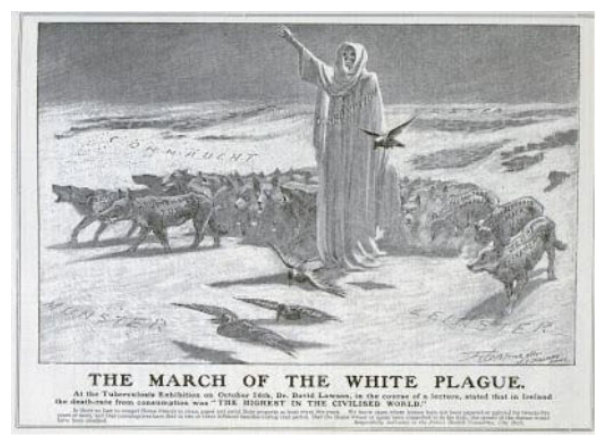

Figure 1. Illustration of white plague caused by Mycobacterium tuberculosis in $1907 .^{7}$

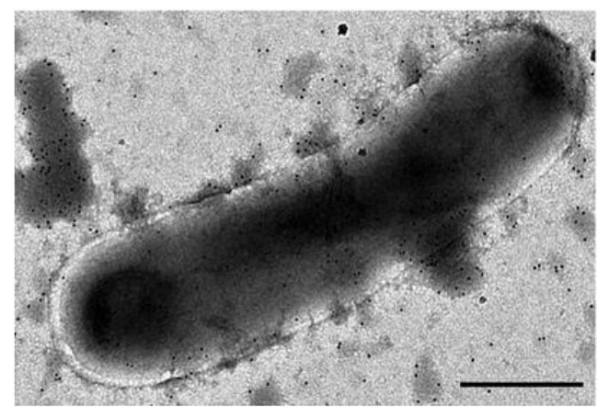

Figure 2. Mycobacterium tuberculosis appearance on electron microscope (scale bar 500 $\mathrm{nm})^{9}$

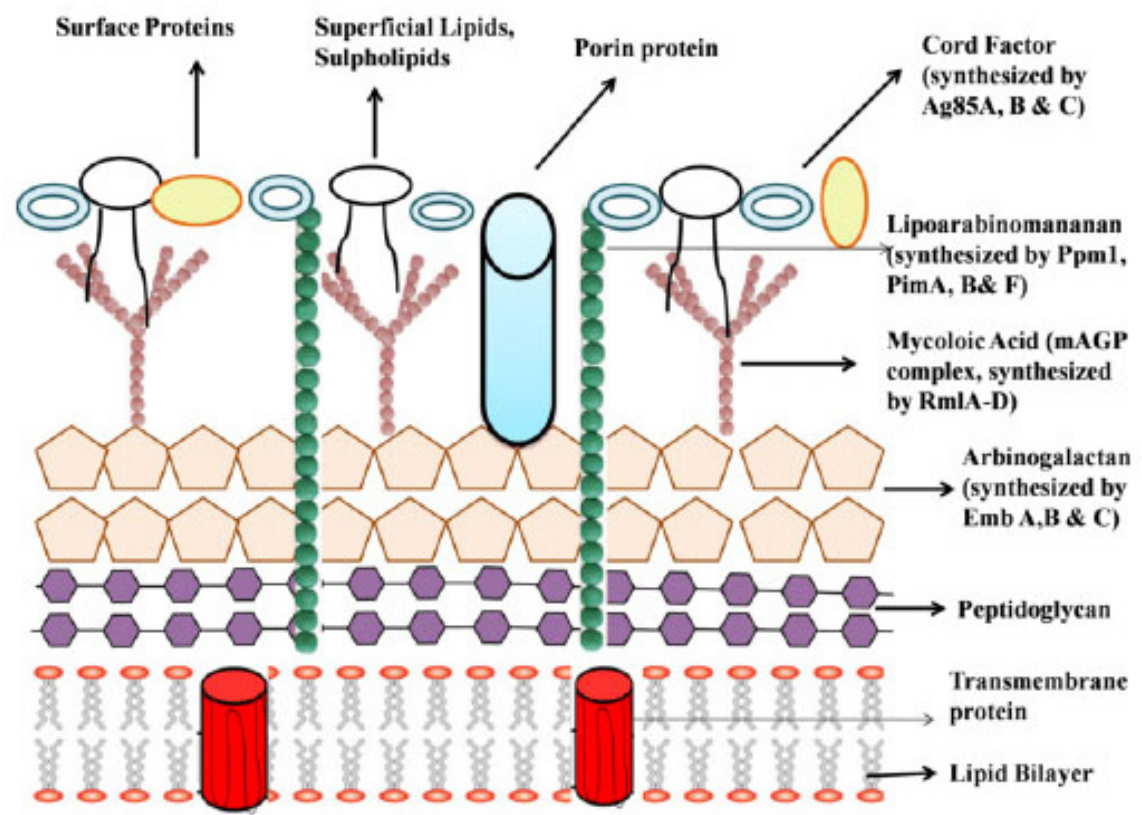

Figure 3. Mycobacterium tuberculosis cell wall components.? 
peptidoglycan. Cell surface of the bacteria not only consists of peptidoglycan, but also lipid that makes them waxy sleeves (Figure 3). Lipid is fractioned into three main attributes such as wax- $\mathrm{D}$, cord factor, and mycolic acid. Mycolic acid has vigorous hydrophobic contributes to its permeability. The mycolic acid is pretty much functions to avert cationic protein and lysozyme in the granule of phagocytic. Moreover, it also intercepts the complement activation, consequently protect the mycobacteria extra cellular. ${ }^{7,8}$

\section{ISOLATION AND IDENTIFICATION OF Mycobacterium tuberculosis}

People who are infected with Mycobacterium tuberculosis usually will present prominent symptoms such as long chronic cough in which in most cases the sputum accompanied by hemoptysis, febrile, sweating at night, weight loss over the months, easy to feel tired and unfit. Being said, people who are clinically suspected got TB exposure will not show any response to any daily treatment's regimen. Moreover, those who just arrived from high endemic of $\mathrm{TB}$ countries or have contact with TB patients should be considered for further tests to confirm the diagnosis. ${ }^{7,8,10}$

According to New South Wales (NSW) Health guidelines, laboratory means to isolate the Mycobacterium tuberculosis from sputum can be done in particular ways. Suspected patients have to be taught how to spell the sputum from their cough properly to obtain the mucopurulent sputum. Sputum must be spelt and collected in early morning in which the samples should be squandered on three consecutive different days in order to obtain high sensitivity. Besides, the other particular time to collect the sputum are spot-spot, or spot-morning, or morning-morning. This mean usually applied to outpatient people considering the convenience. Importantly, collection of sputum from TB high risk people has to be conducted in negative-pressure area or rooms; collection of sputum from lowrisk TB people has to be done in the area with good ventilation and far away from the other patients. To be noted that the samples of sputum should be squandered in such a sterile, with a wrench-lid. ${ }^{11}$
Regarding the culture and smear, the positive result of smear only appears on around $60 \%$ from all specimens those are culture positive. Nevertheless, the smear collection is not able to distinguish Mycobacterium tuberculosis bacillus from the non-TB bacteria hence the smear microscopy has very low sensitivity and specificity. However, the positive smear results shall be managed as tuberculosis until there is proof tell other means. Smear result is obtained in range 24 hours until 48 hours as the specimen has been received and should showing whether the patients infected with TB if acid-fast bacteria is positive. ${ }^{11}$ Microscopical evaluation of acid-fast bacteria from Mycobacterium tuberculosis is shown in Figure $4 .^{7}$

By all means, culture is still become the gold standard to identify the bacteria of TB since it has very high sensitivity, even though not $100 \%{ }^{11}$ Mycobacterium tuberculosis colonies are small and buff colored when grown in Löwenstein-Jensen culture medium (Figure 5). ${ }^{7}$ Identification of Mycobacterium tuberculosis by doing culture will takes around two weeks until eight weeks, however, considering patient cost, culture is much more expensive than smear and have the potential to delay the patient's prompt treatment if waiting the culture result appear due to slow growing of the bacteria. ${ }^{11}$ Nowadays that can be overcome by using rapid molecular test examination with Gene Xpert MTB/ RIF in less than two hours and can identify the presence of Mycobacterium tuberculosis and resistance to rifampicin

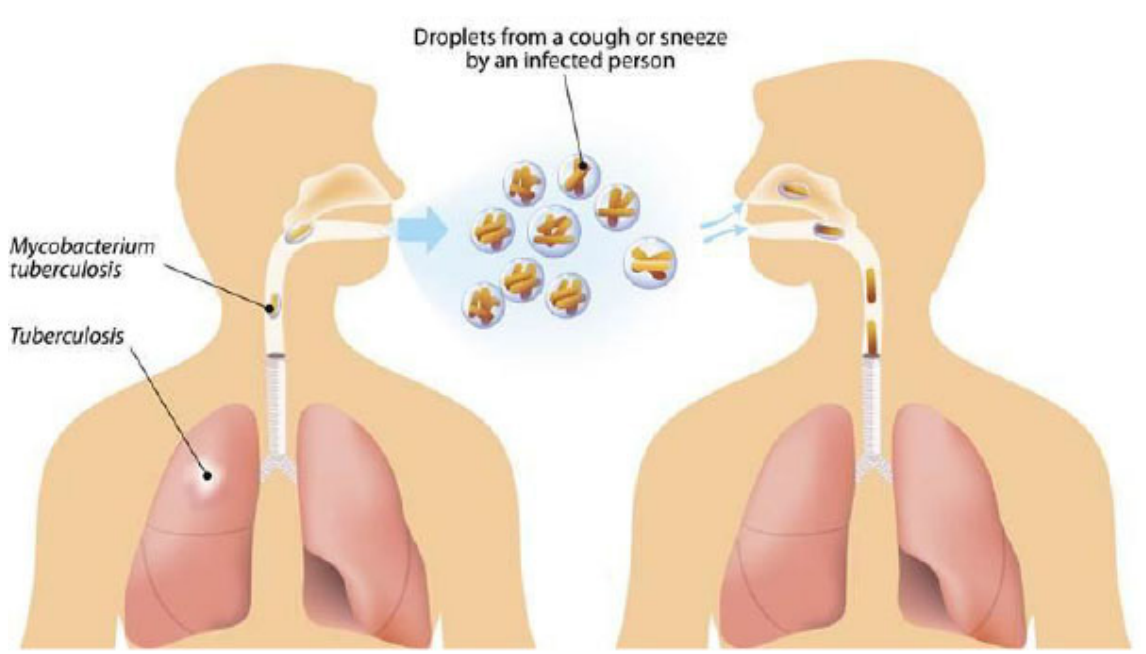

Figure 6. Tuberculosis mainly transmitted through droplets. ${ }^{7}$ simultaneously, therefore the accurate early initiation of therapy can be given and can decrease the incidence of TB in general. The results of large-scale studies indicate that Gene Xpert MTB/RIF has higher sensitivity and specificity for diagnosis of TB than microscopic examination and is closer to the quality of diagnosis by culture

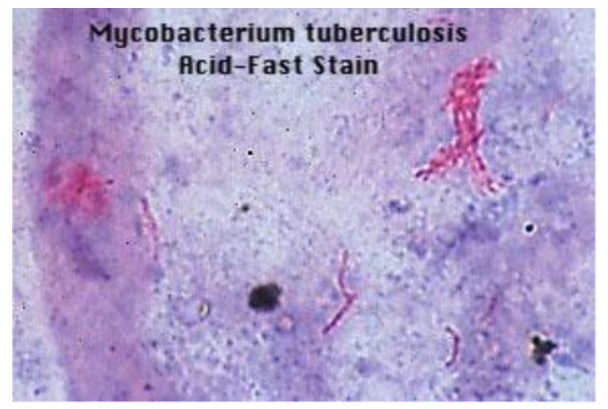

Figure 4. Acid-fast bacilli (AFB) stain of Mycobacterium tuberculosis. ${ }^{7}$

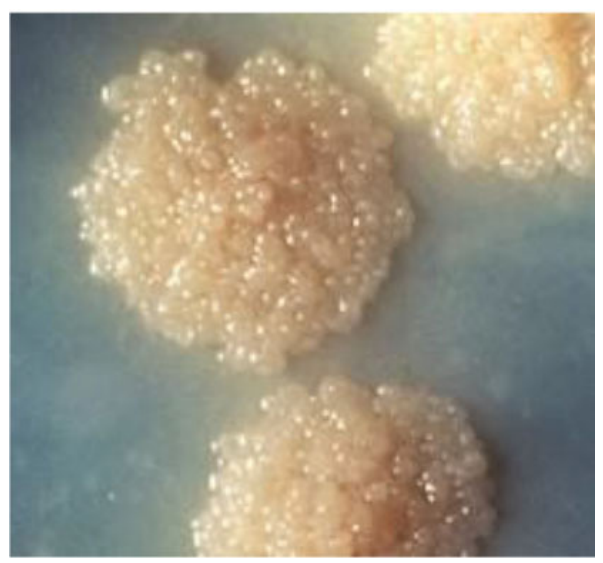

Figure 5. Mycobacterium tuberculosis colonies in Löwenstein-Jensen culture medium. ${ }^{7}$ 


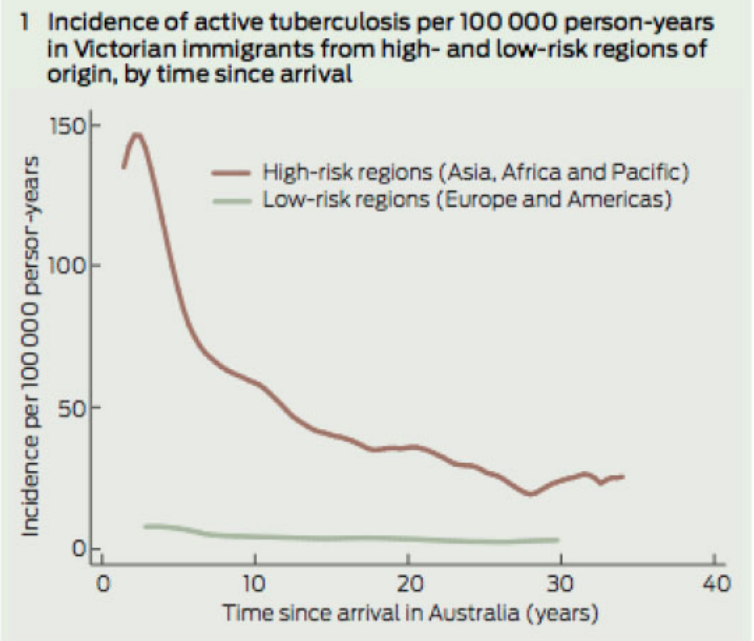

Figure 7. The case incidence of active TB among immigrants in Victoria. ${ }^{13}$

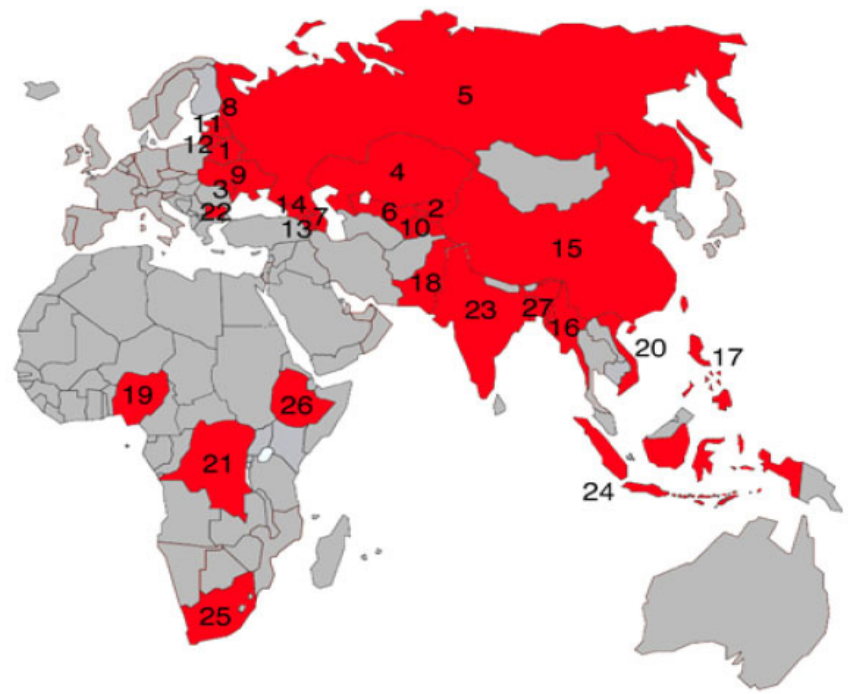

Figure 8. The 27 countries with high MDR-TB burden cases. ${ }^{1}$

examination.

\section{TUBERCULOSIS TRANSMISSION}

The main reservoir of Mycobacterium tuberculosis is human. TB transmission is very important to be known to prevent the spread of disease. It is transmitted by inhaling the TB droplets when the patients coughing, laughing, and sneezing (Figure 6). Furthermore, TB can also be transmitted if people using the same nebulizer and may occur on open abscess drainage. The chance of transmission relies on some factors e.g., exposure duration, the bacteria infectivity, sufficiency of exposure of the bacteria to sun and ventilation. ${ }^{10,11}$

In Australia, TB transmitted through
Mode of TB transmission in Indonesia is pretty much the same with Australia. However, due to its very dense and high population (147 per $\mathrm{km}^{2}$ ), which is around 261.1 million in 2016 (about 3.5 per cent of world population), even worse because there are still many districts or provinces are in poverty, make them the health and sanitation are not main priorities, therefore it is understandable that TB is well known as disease of poverty. The fact of highly dense populated coincides with minimum ventilation of very bad ventilation system in the house, narrow, and humid make TB more easily to spread in those area in Indonesia. Moreover, high cases of TB are happened in malnourished people in Indonesia. Study from Gupta et al., 2009 found that patient with active lung TB had lower nutritional status significantly as malnutrition can causes immunodeficiency leading to high susceptibility to many infections. Furthermore, undetected cases of HIV in Indonesia exacerbate the burden of $\mathrm{TB}$ as finally found that TB easily infect those individuals without even aware that they were immunodeficiency. ${ }^{2,3,5,12}$

\section{CONTROL MEASURES OF TUBERCULOSIS, PUBLIC HEALTH PRIORITY, AND CHALLENGES}

Tuberculosis has become national emerging infectious disease in Australia. Tuberculosis in Australia has currently been monitored by National Notifiable Disease Surveillance System (NNDSS). Under that surveillance system, all the medical practitioners and paramedics are compulsory to delineate TB cases to the health department regularly. Furthermore, National Health Security bears a legal base for information transfer and exchange among the territories in Australia. Being said that, the public health authorities are in charge to make further action in regard to the cases to be notified. Australia has been doing very great TB control during last few decades that leads this country as one of the lowest incidences of TB in last couple years. Nevertheless, the geographical position of Australia to some endemic countries and it is a large immigrant destination in the world means Australia should maintains the great control system in order to minimize the 
TB cases as possible. The cases of active TB cases in immigrants in the Victoria Territory, one of most common immigrant destination territories in Australia is illustrated on Figure 7.,3,5

The surveillance progress in Australia routinely reported along with the trends whether it increase or decrease over period. Moreover, Australian Government and Australian Mycobacterium Reference Laboratory Network (AMRLN) consistently preserve the national accuracy and standard of data presented in surveillance per territory. Regarding to Torres Strait Treaty, islander of the island and coastal resident of Papua New Guinea are permitted to entering Torres Strait Island, Australia and Papua New Guinea in which does not consists of visit to aim for health service. Nonetheless, Papua New Guinea cases remaining represent with TB to Queensland healthcare services in Torres Strait, the diagnosis is being notified in Australia and belong to classification of "Residents of the Torres Strait Protecting Zone (TSPZ) accessing TB treatment in Queensland". Afterwards, patient will be advised to go back to Papua New Guinea for completion of TB treatment. Population data is gained from Australia Bureau of Statistics (ABS). Decreasing the national incidence rate remained the big task challenge in controlling the TB due to its migrant scheme policy. Australian Government also has proposed "Global strategy and targets for tuberculosis prevention, care and control after 2015" aims to eliminates global epidemic of TB by 2035 and diminishes TB incidence up to 90 per cent and reduce mortality due to TB up to 95 per cent. In order to protect the Australia in habitants from TB spread, Department of Home Affairs of Australia in its immigration scheme obliges every applicant who willing to enter Australia for long term to be examined on some $\mathrm{TB}$ screening. In cases where the chest $x$-ray reveals possible of $T B$, the visa applicants will absolutely require further examination to confirm the TB status. Consequently, if the TB is active, that people would not be permitted to enter Australia until complete the treatment and will be re-assessed by health authorities. However, if TB is inactive, visa applicants are still to be required to satisfy health requirements according to Australia immigration policy. ${ }^{3,4,5}$

In Indonesia, the same with Australia, Bacille Calmette-Guérin (BCG) vaccination is strongly effective in decreasing the susceptibility risk of TB. However, in Australia, BCG is strongly advised to individuals with high-risk groups such as Aborigine and Torres Strait inhabitants, baby or child under 5 years old who will travelling or plan residing to high endemic of TB countries, and baby born from parents or family who had history of leprosy. Conversely, all residents in Indonesia are obliged to get BCG vaccine when they were just born in the age of 1-2 months old. Notably, TB is still well known as threat of national development in Indonesia. It is the $3^{\text {rd }}$ major cause of death of $4^{\text {th }}$ cause of disability-adjusted life years (DALYs). National Tuberculosis Control Program (NTP) has achieved big success in treating TB disease, however, early diagnosis and reporting as well as ensuring the patients being treated still become a challenge e.g., around twothirds of new cases giving about 19 per cent of world TB cases missing were under notified called iceberg phenomenon is main public health priority in Indonesia. In addition, study from Surya et al., 2017 found cases notification sourced from private sector was significantly (65 per cent) lower than cases seeking for prompt treatment in those private sectors. Public health care center in Indonesia is the main server for early diagnosis and prompt treatment. Nevertheless, not all health care provider in Indonesia has the sputum smear examinations, especially those in remote areas, they will refer the sputum sample to another public health service or regional hospital which cause delays in early detection and treatments due to waiting the result to be sent back. ${ }^{2,3,4,5,6}$

Both Australia and Indonesia currently facing the crucial problem of multi drugs resistant (MDR-TB) to isoniazid and rifampicin; and extended drugs resistant (XDR-TB) to fluoroquinolone and amikacin or kanamycin or capreomycin. XDR-TB is still rare in Australia but start to emerge in Indonesia. Most cases of MDR-TB in Australia were people who are originally comes from country of 27 high MDR-TB endemics in which Indonesia is one of them close to Australia (Figure 8). ${ }^{1}$ Early diagnosis of MDR-TB and XDR-TB that later implicates on beginning prompt therapy and risk of local spreading become the crucial apprehension of TB elimination in both countries. Detection of MDR-TB depends on culture and drug susceptibility testing (DST). Successful TB treatment could be achieved by routine follow-up of directly observed therapy (DOT) as the duration of treatment is much longer than drug-susceptible TB and its adverse effects. World Health Organization (WHO) advises total treatment duration for MDRTB is 20 months. Patients are strongly being advised to be reassessed upon completion of therapy and monitored the clinical development along with side effects. Moreover, to prevent the disease spreading, education and counseling are mandatory in regard to patients and the household contacts and ensure the community that TB can be cured and preventable if the patients strictly follow the orders of treatment guidelines and surrounding people aware of the way of transmission prevention..$^{2-5,11-15}$

\section{CONCLUSION}

Tuberculosis (TB) cases in Australia remains low compared to Indonesia, however, the close proximity to adjacent developing countries with high endemic of TB contributes significantly to increase number of TB in Australia. Both Australia and Indonesia are currently facing the problems of multi drugs resistant (MDRTB) and TB associated with HIV, but again, the MDR-TB cases in Australia are sourced from the MDR-TB infected people from developing countries. Tuberculosis can be cured in both countries if the patients strictly obeying the treatment guidelines. Patients should be followed up and monitored routinely to ensure the patients being treated and prevent the spreading of disease. Moreover, collaboration between public and private sector along with active collaboration from the family or people surrounding the patients is required to eliminate TB disease.

\section{CONFLICT OF INTEREST}

There is no competing interest regarding the manuscript. 


\section{FUNDING}

None.

\section{AUTHOR CONTRIBUTIONS}

All authors are responsible for the study from the conceptual framework, literature/data gathering, analysis, and implementation of scientific publication.

\section{REFERENCES}

1. World Health Organization. Global tuberculosis report 2019. Geneva; 2019. Available at: https:// www.who.int/tb/publications/global_report/ en/. Accessed on 29 April 2021.

2. Surya A, Setyaningsih B, Nasution HS, Parwati CG, Yuzwar YE, Osberg M, Hanson CL, Hymoff A, Mingkwan P, Makayova J, Gebhard A, Waworuntu W. Quality tuberculosis care in Indonesia: using patients pathway analysis to optimize public private collaboration. Journal of Infectious Diseases. 2017;216:724-732.

3. Australian Government, Department of Health. Tuberculosis notifications in Australia, 2014. Available at: http://www.health.gov.au/internet/ main/publishing.nsf/Content/cdi4103-k. Accessed on 29 April 2021.

4. Australian Government, Department of Home Affairs. Threats to public health. Available at: https://www.homeaffairs.gov.au/trav/visa/heal/ overview-of-the-health-requirement/threatsto-public-health. Accessed on 29 April 2021.

5. Karyadi E, Schultink W, Nelwan RHH, Gross R, Amin Z, Dolmans WMV, Meer JWMV, Hautvast GAJ, West CE. Poor micronutrient status of active pulmonary tuberculosis patients in Indonesia. Journal of Nutrition. 2000;130(12):2953-2958.

6. Parwati I, Crevel RV, Sudiro M, Alisjahbana B, Pakasi T, Kremer K, Zanden AVD, Soolingen DV. Mycobacterium tuberculosis population structures differ significantly on two Indonesia Islands. Journal of Clinical Microbiology. 2008;46(11):3639-3645

7. Talbot EA, Raffa BJ. Mycobacterium tuberculosis. In Molecular Medical Microbiology, $2^{\text {nd }}$ ed; Academic Press: Boston, MA, USA, 2015;3:1637-1653.

8. Smith I. Mycobacterium tuberculosis pathogenesis and molecular determinants of virulence. Clinical Microbiology Reviews. 2003;16(3):463-496.

9. Kalscheuer R, Palacios A, Anso I, Cifuente J, Anguita J, Jacobs Jr WR, Guerin ME and Prados-Rosales R. The Mycobacterium tuberculosis capsule: a cell structure with key implications in pathogenesis. Biochemical Journal. 2019; 476(14):1995-2016.

10. Sulis G, Roggi A, Matteelli A, Raviglione MC. Tuberculosis: epidemiology and control. Mediterr J Hematol Infect Dis. 2014;6(1):e2014070.
11. NSW Government. Tuberculosis. Available at: https://www.health.nsw.gov.au/infectious/ tuberculosis/Pages/default.aspx. Accessed on 29 April 2021

12. Gupta KB, Gupta R, Atreja A, Verma M, Vishvkarma S. Tuberculosis and nutrition. Lung India. 2009:26(1):9-16.

13. McBryde ES, Denholm JT. Risk of active tuberculosis in immigrants: effects of age, region of origin and time since arrival in low-exposure setting. The Medical Journal of Australia. 2012;197: 459-461.

14. Kusumawati RL, Tania T, McNeil E, Chongsuvivatwong V. Predictors of multidrug resistance among pulmonary tuberculosis patients in a tertiary hospital in North Sumatera, Indonesia. Bali Medical Journal. 2018;7(1):6873.

15. Aboltins C, Lynne B, Curtis N, Darby J, Denholm J, Flynn M, Gibney K, Giles M, Graham S, Lane G, Lane D, Leslie D, Ranganathan S, Street A, Streeton J. Management, control and prevention of tuberculosis. Department of Health \& Human Services, State Government of Victoria; 2015

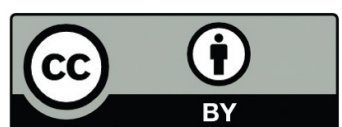

This work is licensed under a Creative Commons Attribution 